Western North American Naturalist 70(1), () 2010, pp. 1-8

\title{
MYCORRHIZATION OF PONDEROSA PINE IN A SECOND-GROWTH SIERRA NEVADA FOREST
}

\author{
R.F. Walker ${ }^{1,3}$, W. Cheng ${ }^{2}$, and D.W. Johnson ${ }^{1}$
}

\begin{abstract}
Ectomycorrhizal colonization and rooting characteristics were quantified in a mature ponderosa pine (Pinus ponderosa Dougl. ex Laws.) stand in the western Sierra Nevada. Root length totaled $3835.9 \mathrm{~m} \cdot \mathrm{m}^{-2}$ of forest floor surface area, with $96 \%$ consisting of the fine-root fraction. Total root dry weight and volume were $2230.4 \mathrm{~g} \cdot \mathrm{m}^{-2}$ and 5807.4 $\mathrm{cm}^{3} \cdot \mathrm{m}^{-2}$ of forest floor area, respectively, with $69 \%$ of the former and $75 \%$ of the latter accounted for by the coarse fraction. Fine roots were most prevalent in the upper $15 \mathrm{~cm}$ of the mineral soil profile, and their abundance declined with increasing depth. Coarse roots were most abundant at a depth of $15-30 \mathrm{~cm}$. Ectomycorrhizal counts totaled $26,814 \cdot \mathrm{m}^{-2}$ of forest floor area, and an overwhelming preponderance was associated with the fine-root fraction. More than three-quarters of mychorrhizae resided in the upper $15 \mathrm{~cm}$ of mineral soil, with an overall trend of declining numbers with increasing depth. Roots and mycorrhizae were exceedingly scarce at a depth of $45-60 \mathrm{~cm}$, and neither was found in the organic soil layer above the mineral profile. A necessary step in understanding the ecophysiological role of mycorrhizae in mature forests is to quantify their abundance in such settings, and the results of this study contribute such information for ponderosa pine.
\end{abstract}

Key words: ectomycorrhizae, mycorrhizal symbiosis, root demography, ponderosa pine.

Mycorrhizal fungi are found in all terrestrial ecosystems (Allen 1991). In forests, mycorrhizal symbioses are considered to be among the more important ecological relationships (Kimmins 2004), conferring substantial benefits to both the trees and their mycobionts. For trees, these benefits include improved nutrition, water relations, and disease resistance; while for mycorrhizal fungi, trees are their primary source of energy (Smith and Read 1997). Efforts to discern advantages derived by the host from ectomycorrhizae, the predominant morphological form in coniferous forests (Fisher and Binkley 2000), have been especially prominent in mycorrhizal research. Among pines alone, certain species of these mycorrhizae have been found to enhance uptake of essential mineral elements (Marx and Artman 1979, Walker et al. 1989, Cumming 1993, Rousseau et al. 1994, Walker and McLaughlin 1997, van Tichelen et al. 1999, Walker 2001, Ahonen-Jonnarth et al. 2003), ameliorate effects of potentially phytotoxic metals (Marx and Artman 1979, Berry 1982, Cumming and Weinstein 1990, Walker and McLaughlin 1997, van Tichelen et al. 1999, Walker 1999, Ahonen-Jonnarth et al. 2003), reduce moisture stress (Duddridge et al. 1980,
Walker et al. 1989), and discourage infections by fungal pathogens (Marx 1973, Chakravarty and Unestam 1987a, 1987b). However, since most research in this realm has been conducted on seedlings in laboratory or greenhouse environments, it is uncertain whether these results can be extrapolated to mature trees in natural settings (Read 2002). Furthermore, fundamental to an understanding of the ecophysiological role of mycorrhizae in mature forests is quantification of their abundance in such settings (Grand and Harvey 1982), but documentation of infection levels in natural forests, as is the case for many plant communities (St. John and Coleman 1983), is largely lacking.

Reported here are quantitative mycorrhization and rooting characteristics in a mature ponderosa pine stand located on the west slope of the Sierra Nevada. Regression analyses were employed to assess the relationships of these characteristics to sampling depth and the relationships of ectomycorrhizal infection to rooting characteristics.

\section{METHODS}

The second-growth ponderosa pine stand selected for study is located in the western

\footnotetext{
${ }^{1}$ University of Nevada, Department of Natural Resources and Environmental Science, 1000 Valley Road, Reno, NV 89512.

${ }^{2}$ University of California, Department of Environmental Studies, 339 Natural Sciences 2, Santa Cruz, CA 95064.

${ }^{3}$ E-mail: walker@cabnr.unr.edu
} 
Sierra Nevada at the Blodgett Forest Research Station $\left(38^{\circ} 52^{\prime} \mathrm{N}, 120^{\circ} 40^{\prime} \mathrm{W}\right)$. It occupies a site at an elevation of $1301 \mathrm{~m}$ with $5 \%$ slope and southeastern aspect. Precipitation averages $158 \mathrm{~cm}$ annually, $78 \%$ of which falls from November through March (Olson and Helms 1996). The soil is of the Holland series (USDA Natural Resources Conservation Service 2008) and has a sandy-loam surface layer with a clayloam subsoil. It is well drained, features an argillic (Btl) horizon at an approximate depth of $50 \mathrm{~cm}$, and is derived from granodiorite.

Four dominant-crown-class ponderosa pine with good growth form were selected from within the stand as subject trees. These were measured for total height, dbh (breast-height bole diameter, measured $1.37 \mathrm{~m}$ above ground), and live-crown length. Tree heights and livecrown lengths were used to calculate live-crown percentage. Each tree was also cored (4.3-mm cores extracted $1.37 \mathrm{~m}$ above ground) to determine age and growth rate. Total age was based on a count of late wood rings from pith to phloem, plus 10 (the latter an approximate number of years needed for Sierra Nevada conifers to produce their first countable ring at breast height; Dunning 1942). Growth rate was determined by counting the rings in the outer $2.54 \mathrm{~cm}$ of each core. Tree height and age were used to assess site quality based on the site index (SI) curves of Meyer (1938). Stand basal area was approximated using a wedge prism at 8 randomly selected sampling points within the stand (Avery and Burkhart 2002).

For investigation of ectomycorrhizal colonization and rooting characteristics, 4 cylindrical soil cores were extracted at each subject tree. Two cores were positioned at the crown drip line; the third core was positioned at the midpoint between the tree bole and its drip line; and the fourth was positioned outside the drip line at the same distance from the drip line as the third core. All cores were oriented in a randomly chosen cardinal direction and extracted on a single day in June. Core diameter was $10 \mathrm{~cm}$, and coring depth was $60 \mathrm{~cm}$ into mineral soil. The $\mathrm{O}$ horizon at the top of each core was measured for depth and assessed for root and ectomycorrhizal presence. Mineral soil cores were then retrieved in 4 sections at depths of $0-15,15-30,30-45$, and $45-60 \mathrm{~cm}$. All root segments in every core section were harvested immediately by sieving and washing and were stored at $4{ }^{\circ} \mathrm{C}$. Diameter and length of every root segment were subsequently measured, and the segments were divided into fine $(<2.0-\mathrm{mm}$-diameter $)$ and coarse $(\geq 2.0$-mm-diameter) size fractions. Ectomycorrhizal short roots-identified as those with characteristic monopodial, bifurcate, or coralloid form or those displaying a fungal mantle-were counted (Grand and Harvey 1982). Lastly, root-segment volumes were measured by water displacement using the apparatus of Yawney and Carl (1969), and the segments were dried to a constant weight and weighed. Root length, volume, and dry weight were segregated by core, core section, and size fraction and ultimately expressed as values per unit forest floor surface area $(\mathrm{m}$. $\mathrm{m}^{-2}, \mathrm{~cm}^{3} \cdot \mathrm{m}^{-2}$, and $\mathrm{g} \cdot \mathrm{m}^{-2}$, respectively). Length and weight values were used to calculate specific root length $\left(\mathrm{m} \cdot \mathrm{g}^{-1}\right)$, and ectomycorrhizal infection was expressed as both the mycorrhizal count per unit forest floor surface area $\left(\# \cdot \mathrm{m}^{-2}\right)$ and mycorrhizal count per unit root length $\left(\# \cdot \mathrm{m}^{-1}\right)$. Sporocarps encountered on the forest floor were identified using the field guide of Lincoff (1981) to determine possible mycobiont species.

Data were analyzed using repeated-measures mixed-model ANOVA incorporating the first-order autoregressive covariance structure. Nesting of soil core within tree permitted examination of within- and between-tree variation. Tree and depth effects, along with their interactions, were considered significant when $P \leq 0.05$ according to the $F$ test. The standard error of the mean (SE) was calculated to provide an indication of the variation among the values from which each mean was derived. Simple linear regression models were used to discern whether significant correlations existed between selected independent and dependent variables. One subset of these models incorporated sample depth as the independent variable, with root diameter, length, weight, volume, specific length, and mycorrhization values (all segregated by size fraction and with mycorrhization values expressed as both $\# \cdot \mathrm{m}^{-2}$ and \# $\cdot \mathrm{m}^{-1}$ ) as the dependent variables. The second subset was confined to the fine fraction and featured root diameter, length, weight, volume, and specific length as independent variables with mycorrhization values $\left(\# \cdot \mathrm{m}^{-2}\right.$ and $\# \cdot \mathrm{m}^{-1}$ ) as the dependent variables. The third subset included the same independent 
TABLE 1. Root demography and mycorrhization of dominant crown class ponderosa pine in a pure stand on the west slope of the Sierra Nevada. Each value is the mean of 16 soil cores divided equally among 4 trees $(n=4)$, and indicated parenthetically is the standard error of the mean.

\begin{tabular}{cccccccc}
\hline $\begin{array}{l}\text { Depth } \\
(\mathrm{cm})\end{array}$ & $\begin{array}{c}\text { Diameter } \\
(\mathrm{mm})\end{array}$ & $\begin{array}{c}\text { Length } \\
\left(\mathrm{m} \cdot \mathrm{m}^{-2}\right)\end{array}$ & $\begin{array}{c}\text { Dry weight } \\
\left(\mathrm{g} \cdot \mathrm{m}^{-2}\right)\end{array}$ & $\begin{array}{c}\text { Volume } \\
\left(\mathrm{cm}^{3} \cdot \mathrm{m}^{-2}\right)\end{array}$ & $\begin{array}{c}\text { Specific length } \\
\left(\mathrm{m} \cdot \mathrm{g}^{-1}\right)\end{array}$ & $\begin{array}{c}\text { Mycorrhizae } \\
\left(\# \cdot \mathrm{m}^{-2}\right)\end{array}$ & $\left(\# \cdot \mathrm{m}^{-1}\right)$ \\
\hline FINE ROOT FRACTION & & & & & & & \\
$0-15$ & $0.38(0.01)$ & $1832.9(199.5)$ & $323.2(33.8)$ & $732.5(98.8)$ & $5.78(0.26)$ & $21,067(3416)$ & $12.3(1.4)$ \\
$15-30$ & $0.38(0.01)$ & $1106.5(139.7)$ & $210.9(13.3)$ & $445.9(29.1)$ & $5.26(0.43)$ & $3416(458)$ & $3.3(0.8)$ \\
$30-45$ & $0.42(0.04)$ & $585.0(63.3)$ & $125.3(12.3)$ & $230.9(30.1)$ & $4.84(0.37)$ & $1967(262)$ & $3.2(0.6)$ \\
$45-60$ & $0.45(0.03)$ & $148.2(12.8)$ & $33.1(3.1)$ & $59.6(6.3)$ & $4.44(0.29)$ & $298(52)$ & $1.9(0.3)$ \\
COARSE ROOT FRACTION & & & & & & \\
$0-15$ & $3.26(0.09)$ & $43.0(7.4)$ & $187.6(32.0)$ & $517.5(77.3)$ & $0.29(0.01)$ & $8(8)$ & $4.8(3.6)$ \\
$15-30$ & $4.98(0.34)$ & $59.9(9.8)$ & $703.3(186.8)$ & $1934.7(534.9)$ & $0.16(0.04)$ & $32(22)$ & $0.6(0.5)$ \\
$30-45$ & $5.61(0.87)$ & $47.6(9.4)$ & $504.4(190.4)$ & $1472.9(561.4)$ & $0.23(0.04)$ & $24(24)$ & $0.8(0.7)$ \\
$45-60$ & $8.91(0.61)$ & $12.8(2.4)$ & $142.6(34.1)$ & $413.4(91.4)$ & $0.11(0.01)$ & $2(1)$ & $0.2(0.1)$ \\
\hline
\end{tabular}

and dependent variables as those in the second subset, but all values were derived from the coarse fraction. Regression models were considered significant when $P \leq 0.05$ according to the $F$ test. All statistical analyses were performed using SAS (SAS Institute, Inc., Cary, NC).

\section{RESULTS}

On average, the 4 subject trees were 41.4 $\mathrm{m}$ tall (range 38.7-43.6 m), were $80.2 \mathrm{~cm} \mathrm{dbh}$ (range 73.4-94.2 cm), had 46\% live crown (range $42-50 \%$ ), and were 84 years old (range 79-89 years). Radial growth averaged 3.1 rings $\cdot \mathrm{cm}^{-1}$ (range 2.4-3.5 rings $\cdot \mathrm{cm}^{-1}$ ), which equates to recent annual diameter growth of $0.6 \mathrm{~cm}$ (range $0.6-0.8 \mathrm{~cm}$ ). Subject trees occupied an $\mathrm{SI}_{100} 43$ site (index height in meters). The basal area for the stand was $36 \mathrm{~m}^{2} \cdot \mathrm{ha}^{-1}$.

Within the fine-root fraction, root length, weight, and volume declined sequentially with sampling depth (all $P<0.0001$ ) in mineral soil (Table 1). Fifty percent of the length and $50 \%$ of the volume were found in the upper $15 \mathrm{~cm}$, and $80 \%$ of each was in the upper $30 \mathrm{~cm}$; but for both, only $4 \%$ was located at the $45-60-\mathrm{cm}$ depth. Similarly, $47 \%$ and $77 \%$ of the weight was found in the upper 15 and $30 \mathrm{~cm}$, respectively, while 5\% existed in the deepest stratum. Totaled across all 4 depths, fine-root length amounted to $3672.6 \mathrm{~m} \cdot \mathrm{m}^{-2}$ of forest floor surface area, while dry weight totaled $692.5 \mathrm{~g}$. $\mathrm{m}^{-2}$ and volume totaled $1468.9 \mathrm{~cm}^{3} \cdot \mathrm{m}^{-2}$. Statistically, fine-root diameter was unaffected by depth $(P=0.4403)$, but some evidence that roots in this fraction became more coarse the deeper they grew was provided by specific length, which decreased with depth $(P=$
0.0493). The 4 subject trees also differed in fine-root length $(P=0.0006)$, weight $(P=$ $0.0051)$, volume $(P=0.0015)$, and specific length $(P=0.0356)$. However, the extent of such differences varied by depth for length, weight, and volume, as the tree $\times$ depth interaction effect was significant for these variables $(P=0.0434, P=0.0149$, and $P=0.0242$, respectively).

For the coarse-root fraction, root length was not significantly influenced by sampling depth $(P=0.3185)$, but weight $(P=0.0347)$ and volume $(P=0.0474)$ were (Table 1$)$. The greatest weight and volume were found at the 15-30$\mathrm{cm}$ depth, amounting to $46 \%$ and $45 \%$ of the respective totals; and for each, $78 \%$ resided in the 2 middle strata. Coarse-root weight and volume were lowest at the $45-60-\mathrm{cm}$ depth, where only $9 \%$ of each was found. Across all 4 strata, total length of the coarse fraction was $163.3 \mathrm{~m} \cdot \mathrm{m}^{-2}$ of forest floor area, while the weight and volume totals were $1537.9 \mathrm{~g} \cdot \mathrm{m}^{-2}$ and $4338.5 \mathrm{~cm}^{3} \cdot \mathrm{m}^{-2}$, respectively. Coarseroot diameter tended to increase with depth $(P=0.0474)$, while specific length tended to decrease $(P=0.0497)$. Rooting differences among subject trees in the coarse fraction were significant only for length $(P=0.0020)$ and weight $(P=0.0411)$.

Within the fine-root fraction, ectomycorrhizal counts per unit forest floor area $(P<$ $0.0001)$ and per unit root length $(P=0.0007)$ declined sequentially with depth (Table 1). For the former, $79 \%$ of all mycorrhizae were found in the upper $15 \mathrm{~cm}$ and only $1 \%$ at $45-60 \mathrm{~cm}$. Similarly, the count per unit root length in the upper stratum was approximately 6.5 times that at the deepest depth. Across all strata, the count per unit forest floor area totaled $26,748 \cdot \mathrm{m}^{-2}$ 
TABLE 2. Significant simple linear regressions relating root demography and mycorrhization to sample depth, and mycorrhization to root demography. All models incorporate measurements derived from 64 samples $(n=64)$.

\begin{tabular}{lcccr}
\hline Independent variable & Dependent variable & Correlation & $P$ value $(F$ test) for model & $R^{2}$ \\
\hline VERTICAL DISTRIBUTION & & & & \\
Sample depth & Fine root length & Negative & $<0.0001$ & 0.5655 \\
Sample depth & Fine root dry weight & Negative & $<0.0001$ & 0.5768 \\
Sample depth & Fine root volume & Negative & $<0.0001$ & 0.4482 \\
Sample depth & Specific fine root length & Negative & 0.0272 & 0.1084 \\
Sample depth & Fine root mycorrhizae $\left(\# \cdot \mathrm{m}^{-2}\right)$ & Negative & $<0.0001$ & 0.3360 \\
Sample depth & Fine root mycorrhizae $\left(\# \cdot \mathrm{m}^{-1}\right)$ & Negative & 0.0007 & 0.2373 \\
Sample depth & Coarse root diameter & Positive & 0.0131 & 0.1348 \\
FINE ROOT FRACTION & & & & \\
Diameter & Mycorrhizae $\left(\# \cdot \mathrm{m}^{-2}\right)$ & Negative & 0.0499 & 0.1609 \\
Length & Mycorrhizae $\left(\# \cdot \mathrm{m}^{-2}\right)$ & Positive & $<0.0001$ & 0.3073 \\
Length & Mycorrhizae $\left(\# \cdot \mathrm{m}^{-1}\right)$ & Positive & 0.0351 & 0.0929 \\
Dry weight & Mycorrhizae $\left(\# \cdot \mathrm{m}^{-2}\right)$ & Positive & $<0.0001$ & 0.4087 \\
Dry weight & Mycorrhizae $\left(\# \cdot \mathrm{m}^{-1}\right)$ & Positive & 0.0017 & 0.1941 \\
Volume & Mycorrhizae $\left(\# \cdot \mathrm{m}^{-2}\right)$ & Positive & $<0.0001$ & 0.4514 \\
Volume & Mycorrhizae $\left(\# \cdot \mathrm{m}^{-1}\right)$ & Positive & 0.0027 & 0.1796 \\
COARSE ROOT FRACTION & & & & \\
Diameter & Mycorrhizae $\left(\# \cdot \mathrm{m}^{-2}\right)$ & Positive & $<0.0001$ & 0.3168 \\
Dry weight & Mycorrhizae $\left(\# \cdot \mathrm{m}^{-2}\right)$ & Positive & 0.0024 & 0.1948 \\
Volume & Mycorrhizae $\left(\# \cdot \mathrm{m}^{-2}\right)$ & Positive & 0.0005 & 0.2505 \\
\hline
\end{tabular}

within the fine fraction, averaging $5.2 \cdot \mathrm{m}^{-1}$ of root length. In contrast, the count across the 4 depths only totaled $66 \cdot \mathrm{m}^{-2}$ of surface area for the coarse root fraction, with $1.6 \cdot \mathrm{m}^{-1}$ of length. Furthermore, neither the count per unit forest floor area $(P=0.7293)$ nor the count per unit root length $(P=0.5978)$ was significantly influenced by depth. For both fineand coarse-root fractions, differences among subject trees in the counts per unit area $(P=$ 0.7771 and $P=0.3087$, respectively) and counts per unit length $(P=0.6145$ and $P=$ 0.3614 , respectively) were not significant, and neither were the tree $\times$ depth interaction effects for these variables $(P=0.6630$ and $P=$ 0.6114 for the counts per unit area within the fine and coarse fractions, respectively, and $P$ $=0.9463$ and $P=0.6102$ for counts per unit length within the respective fractions).

The $\mathrm{O}$ horizon samples collected at the top of each mineral soil core averaged $8.4 \mathrm{~cm}$ in depth (range 6.3-9.7 cm) but were devoid of either fine or coarse roots and thus of ectomycorrhizal short roots. Field identification of sporocarps inhabiting the study site during core extraction indicated the presence of 2 possible ectomycorrhizal species: Rhizopogon occidentalis Zel. \& Dod. and Suillus granulatus (L. ex Fr.) Kuntze.

Of the simple regression models developed with sampling depth as the independent variable, 7 proved to be significant, and all but one of the significant models incorporated values derived from the fine-root fraction as dependent variables (Table 2). Among the models involving the fine-root fraction, root length, weight, volume, and specific length, along with mycorrhizal counts per unit forest floor area and mycorrhizal counts per unit root length, were negatively related to depth. Of these models, the 2 involving root length and weight yielded the highest $R^{2}$ values, with both explaining more than one-half of the variation in the dependent variables; while the model involving specific root length had the lowest $R^{2}$. The lone significant model involving the coarse fraction with depth as the independent variable revealed a positive but weak relationship between root diameter and depth.

Of the regression models developed to examine relationships between root demography and mycorrhizal colonization within the fineroot fraction, 7 were significant (Table 2). The lone negative correlation among these 7 models related mycorrhizal count per unit forest floor area to root diameter; positive relationships were revealed between both the counts per unit area and per unit root length and the independent variables of root length, weight, and volume. Of these models, however, only the 2 relating mycorrhizal counts per unit area to weight and volume explained more than $40 \%$ of the variation in this dependent variable. 
For the coarse-root fraction, models computed to discern relationships between root demography and mycorrhizal colonization yielded only 3 that were significant (Table 2). These models revealed positive correlations between mycorrhizal count per unit forest floor area and root diameter, weight, and volume. Only the model involving mycorrhization and root diameter explained more than $30 \%$ of the variation in the dependent variable.

\section{Discussion}

Ectomycorrhizae represent an obligate symbiosis for pine species (Meyer 1973, Kottke 2002, Dahm 2005) to the extent that all pines growing in natural field substrates have these associations (Kimmins 2004). Because ectomycorrhizae constitute such an integral component of their root systems, quantification of the mycorrhizal colonization of pines in field settings necessitates an assessment of overall root demography as well.

In this study of mature ponderosa pine growing on a highly productive Sierra Nevada site, total root length amounted to $3835.9 \mathrm{~m}$ - $\mathrm{m}^{-2}$ of forest floor surface area, $96 \%$ of which was in the fine-root fraction. In contrast, for total root dry weight and volume, which were $2230.4 \mathrm{~g} \cdot \mathrm{m}^{-2}$ and $5807.4 \mathrm{~cm}^{3} \cdot \mathrm{m}^{-2}$ of forest floor area, respectively, $69 \%$ of the former and $75 \%$ of the latter were accounted for by the coarse fraction. Thus, fine roots compose a preponderance of the length but little of the biomass in ponderosa pine root systems, while coarse roots compose most of the biomass but little of the length. This finding supports prevailing assumptions about basic root demography in forest trees (Kozlowski and Pallardy 1997).

The disparity here between the fine and coarse fractions in comparative length and weight was also evident in specific length, which was approximately 26 times greater in fine roots. Another pronounced difference between the 2 size fractions was the depth in mineral soil at which each predominantly resided. Regardless of the measure used, fine roots were most prevalent at a depth of 0-15 $\mathrm{cm}$, and more than three-quarters of them occurred in the upper $30 \mathrm{~cm}$; coarse roots were most prevalent at a depth of $15-30 \mathrm{~cm}$, and two-thirds or more, depending on the measure, were found at $15-45 \mathrm{~cm}$. Given the critical role of fine roots in nutrient uptake and the tendency for nutrients to be most abundant in the upper soil profile (Fisher and Binkley 2000), a preponderance of the fine roots of ponderosa pine near the mineral soil surface is logical. It is also concordant with findings from root studies of other pines (Parker and van Lear 1996, Achat et al. 2008).

A commonality shared by the 2 fractions, however, was that few of either fine or coarse roots resided at the deepest stratum of 45-60 $\mathrm{cm}$, although the latter were more prevalent proportionally at this depth than the former. Few roots were found at the deepest depth regardless of size, and the argillic horizon within this stratum likely impedes root penetration deeper into the soil profile. Thus, it is reasonably assumed that the coring depth used here captured a high proportion of the vertical root distribution for this forest stand. The absence of any roots within the $\mathrm{O}$ horizon at this site reflects the scarce growing-season precipitation in the Sierra Nevada. Such climate regimes frequently result in very dry organic layers (Kimmins 2004) which are inhospitable to root development.

Due to the arduous nature of acquiring data, quantitative assessments of ectomycorrhizal colonization levels in mature forests are rare. However, to build upon the large body of studies conducted to date on immature plants in controlled environments, mycorrhizal research in the future should focus on investigations in natural settings in order to answer questions of ecological relevance (Smith and Read 1997). A critical component of such research is the quantification of mycorrhizal populations in field substrates supporting native plant communities (St. John and Coleman 1983).

In this study, the number of ectomycorrhizae emanating from the roots of ponderosa pine totaled $26,814 \cdot \mathrm{m}^{-2}$ of forest floor area, and nearly all were a component of the fineroot fraction. Further evidence of the mycorrhizal affinity for fine roots was the number per unit root length, which averaged $3.4 \cdot \mathrm{m}^{-1}$ overall but was over 3 times higher in fine roots than in coarse roots, despite a total length for the former that was more than 22 times that for the latter. More than three-quarters of the total mycorrhizae were found at the 0-15-cm depth in mineral soil. Given the aforementioned tendency for nutrients to be most abundant in the upper soil profile, this finding corroborates the view that ectomycorrhizae 
are essential in nutrient absorption by the host plant (Simard et al. 2002).

However, substantial numbers of mycorrhizae were also found in association with fine roots at the $15-30-\mathrm{cm}$ and even the $30-45-\mathrm{cm}$ depths. This finding suggests that the nearly exclusive proliferation of ectomycorrhizae in mineral soil just below the organic horizon reported for some pines (Smith and Read 1997) does not hold entirely true for ponderosa pine. The low counts obtained in the deepest stratum sampled, which included the argillic horizon, indicate that the coring depth used here probably captured the entire vertical mycorrhizal distribution. Also, the complete absence of mycorrhizae in the $\mathrm{O}$ horizon is a departure from findings in other forests with prolific ectomycorrhizal associations (Smith and Read 1997). This absence likely reflects the desiccation of the $\mathrm{O}$ horizon during the growing season.

Given the difficulty of identifying fungal taxa involved in the mycorrhizal symbioses existing in natural environments (Allen 1991), the observation of $R$. occidentalis and S. granulatus at this study site suggests the possible presence of what may be an array of indigenous mycobionts, as it is common for several mycorrhizal species to coexist on a single root system in pines (Smith and Read 1997). Furthermore, although these 2 fungi are known ectomycorrhizal symbionts of ponderosa pine (Trappe 1962, Molina and Trappe 1982), it is also probable that a succession of mycobionts infect individual trees over time (Bledsoe 1992).

To varying degrees, the regression analysis used here further substantiated the influences of sampling depth on fine-root demography and mycorrhization. Values derived from the fine-root fraction combined with depth to yield significant models for every variable, either measured or computed, except root diameter. In each significant model, increases in depth were related to decreases in the dependent variable. However, only in the 2 models involving fine-root length and weight did depth explain as much as one-half of the variation in the dependent variable. In contrast, among values derived from the coarse fraction, root diameter alone was related to depth, with the associated model revealing an increase in diameter as depth increased. Regardless, little of the variation in diameter was explained by the model.

Of significant models concerned with relationships between mycorrhization and root demography within the fine fraction, none accounted for as much as one-half of the variation in mycorrhizal development. Nevertheless, these models revealed that mycorrhizal count, expressed as the number per unit forest floor area, declined as root diameter increased but mycorrhizal count increased with increasing length, weight, and volume of fine roots, whether expressed as the number per unit area or per unit root length.

Among models involving mycorrhization and root demography within the coarse fraction, only a small proportion was significant. Again, none of the models accounted for as much as one-half of the variation in mycorrhizal development; but these models also revealed an increase in mycorrhizal count with increasing weight and volume when the count was expressed as the number per unit area. One model in this group, however, indicated an increase in mycorrhization with increasing coarse-root diameter, which was a departure from the relationship demonstrated in the fine fraction.

In summary, rooting characteristics and mycorrhization were quantified in a mature, second-growth ponderosa pine stand occupying a highly productive site in the western Sierra Nevada. Fine roots comprised most of the root system length but little of its biomass, while coarse roots comprised most of the biomass but little of the length. Distinct vertical stratification of the 2 size fractions was evident, with fine roots most prevalent in the upper $15 \mathrm{~cm}$ of mineral soil while coarse roots were most abundant at $15-30 \mathrm{~cm}$. Ectomycorrhizae were numerous, especially near the mineral soil surface, and were overwhelmingly associated with the fine-root fraction. A pronounced scarcity of roots, regardless of size fraction, and of mycorrhizae was apparent at a 45-60-cm depth in mineral soil (the deepest stratum sampled), and neither roots nor mycorrhizae resided in the organic soil layer above the mineral profile. The generally weak nature of the associations between the independent and dependent variables revealed by regression analysis in this study reflects the variability inherent in naturally regenerated forests. It also suggests that factors beyond the scope of 
the study exert strong influences on both root and mycorrhizal demography.

\section{ACKNOWLEDGMENTS}

Funding for this research was provided by the National Science Foundation and the Nevada Agricultural Experiment Station. We thank J. Chacon, C. McCarthy, W. Frederick, and the staff of the Blodgett Forest Research Station for their assistance.

\section{Literature Cited}

AChat, D.L., M.R. Bakker, And P. Trichet. 2008. Rooting patterns and fine root biomass of Pinus pinaster assessed by trench wall and core methods. Journal of Forest Research 13:165-175.

Ahonen-Jonnarth, U., A. Goransson, and R.D. Finlay 2003. Growth and nutrient uptake of ectomycorrhizal Pinus sylvestris seedlings in a natural substrate treated with elevated $\mathrm{Al}$ concentrations. Tree Physiology 23:157-167.

ALLEN, M.F. 1991. The ecology of mycorrhizae. Cambridge University Press, New York, NY

Avery, T.E., AND H.E. BurKharT. 2002. Forest measurements. 5th edition. McGraw-Hill, New York, NY.

BERRY, C.R. 1982. Survival and growth of pine hybrid seedlings with Pisolithus ectomycorrhizae on coal spoils in Alabama and Tennessee. Journal of Environmental Quality 11:709-715.

BLedsoe, C.S. 1992. Physiological ecology of ectomycorrhizae: implications for field application. Pages 424-437 in M.F. Allen, editor, Mycorrhizal functioning: an integrative plant-fungal process. Chapman and Hall, New York, NY.

Chakravarty, P., and T. Unestam. 1987a. Mycorrhizal fungi prevent disease in stressed pine seedlings. Journal of Phytopathology 118:335-340.

. 1987b. Differential influence of ectomycorrhizae on plant growth and disease resistance of Pinus sylvestris seedlings. Journal of Phytopathology 120: 104-120.

Cumming, J.R. 1993. Growth and nutrition of nonmycorrhizal and mycorrhizal pitch pine (Pinus rigida) seedlings under phosphorus limitation. Tree Physiology 13:173-187.

Cumming, J.R., And L.H. Weinstein. 1990. Aluminummycorrhizal interactions in the physiology of pitch pine seedlings. Plant and Soil 125:7-18.

DAнм, H. 2005. Role of mycorrhizae in forestry. Pages 241-270 in M.K. Rai, editor, Handbook of microbial biofertilizers. Haworth Press, Binghamton, NY.

Duddridge, J.A., A. Malibari, And D.J. Read. 1980. Structure and function of mycorrhizal rhizomorphs with special reference to their role in water transport. Nature 287:834-836.

DunNING, D. 1942. A site classification for the mixed conifer selection forests of the Sierra Nevada. USDA Forest Service, California Forest and Range Experiment Station Research Note 28, Berkeley, CA

Fisher, R.F., AND D. Binkley. 2000. Ecology and management of forest soils. 3rd edition. John Wiley \& Sons, New York, NY.
Grand, L.F., And A.E. Harvey. 1982. Quantitative measurement of ectomycorrhizae on plant roots. Pages 157-164 in N.C. Schenck, editor, Methods and principles of mycorrhizal research. American Phytopathological Society, St. Paul, MN.

Kimmins, J.P. 2004. Forest ecology. 3rd edition. Prentice Hall, Upper Saddle River, NJ.

KotTKe, I. 2002. Mycorrhizae: rhizosphere determinants of plant communities. Pages 919-932 in Y. Waisel, A. Eshel, and U. Kafkafi, editors, Plant roots: the hidden half. 3rd edition. Marcel Dekker, New York, NY.

Kozlowski, T.T., and S.G. Pallardy. 1997. Physiology of woody plants. 2nd edition. Academic Press, New York, NY.

Lincoff, G.H. 1981. The Audubon Society field guide to North American mushrooms. Alfred A. Knopf, New York, NY.

MaRX, D.H. 1973. Mycorrhizae and feeder root diseases. Pages 351-382 in G.C. Marks and T.T. Kozlowski, editors, Ectomycorrhizae: their ecology and physiology. Academic Press, New York, NY.

Marx, D.H., AND J.D. Artman. 1979. Pisolithus tinctorius ectomycorrhizae improve survival and growth of pine seedlings on acid coal spoils in Kentucky and Tennessee. Reclamation Review 2:23-31.

Meyer, F.H. 1973. Distribution of ectomycorrhizae in native and man-made forests. Pages 79-105 in G.C. Marks and T.T. Kozlowski, editors, Ectomycorrhizae: their ecology and physiology. Academic Press, New York, NY.

MEYER, W.H. 1938. Yield of even-aged stands of ponderosa pine. USDA Technical Bulletin 630, Washington, DC.

Molina, R., AND J.M. Trappe. 1982. Patterns of ectomycorrhizal host specificity and potential among Pacific Northwest conifers and fungi. Forest Science 28: 423-458.

Olson, C.M., AND J.A. HeLms. 1996. Forest growth and stand structure at Blodgett Forest Research Station 1933-1995. Pages 681-732 in Status of the Sierra Nevada. Volume 3, Assessments, commissioned reports, and background information. University of California, Wildland Resources Center Report 38, Davis, CA.

PARKER, M.M., AND D.H. VAN LEAR. 1996. Soil heterogeneity and root distribution of mature loblolly pine stands in Piedmont soils. Soil Science Society of America Journal 60:1920-1925.

READ, D.J. 2002. Towards ecological relevance: progress and pitfalls in the path towards an understanding of mycorrhizal functions in nature. Pages 3-29 in M.G.A. van der Heijden and I.R. Sanders, editors, Mycorrhizal ecology. Springer-Verlag, New York, NY.

Rousseau, J.V.D., D.M. Sylvia, And A.J. Fox. 1994. Contribution of ectomycorrhiza to the potential nutrient-absorbing surface of pine. New Phytologist 128: 639-644.

Simard, S.W., M.D. Jones, and D.M. Durall. 2002. Carbon and nutrient fluxes within and between mycorrhizal plants. Pages 33-74 in M.G.A. van der Heijden and I.R. Sanders, editors, Mycorrhizal ecology. Springer-Verlag, New York, NY.

Smith, S.E., AND D.J. READ. 1997. Mycorrhizal symbiosis. 2nd edition. Academic Press, New York, NY.

ST. John, T.V., and D.C. Coleman. 1983. The role of mycorrhizae in plant ecology. Canadian Journal of Botany 61:1005-1014. 
Trappe, J.M. 1962. Fungus associates of ectotrophic mycorrhizae. Botanical Review 28:538-606.

USDA Natural Resources Conservation Service. 2008. Holland series [online]. Available from: http://soils .usda.gov/technical/classification/osd/index.html

Van Tichelen, K.K., T. Vanstraelen, and J.V. Colpaert. 1999. Nutrient uptake by intact mycorrhizal Pinus sylvestris seedlings: a diagnostic tool to detect copper toxicity. Tree Physiology 19:189-196.

WALKER, R.F. 1999. Reforestation of an eastern Sierra Nevada surface mine: seedling growth and nutritional responses to controlled release fertilization and ectomycorrhizal inoculation. Journal of Sustainable Forestry 9(3/4):127-147.

2001. Growth and nutritional responses of containerized sugar and Jeffrey pine seedlings to controlled release fertilization and induced mycorrhization. Forest Ecology and Management 149: 163-179.
Walker, R.F., and S.B. McLaughlin. 1997. Effects of acidic precipitation and ectomycorrhizal inoculation on growth, mineral nutrition, and xylem water potential of juvenile loblolly pine and white oak. Journal of Sustainable Forestry 5(3/4):27-49.

Walker, R.F., D.C. West, S.B. McLaughlin, and C.C. AMUNDSEN. 1989. Growth, xylem pressure potential, and nutrient absorption of loblolly pine on a reclaimed surface mine as affected by an induced Pisolithus tinctorius infection. Forest Science 35: 569-581.

YaWnEY, H.W., AND C.M. CARL. 1969. An improved seedling root-volume measuring device. Tree Planters' Notes 20(3):7-8.

Received 7 August 2008 Accepted 8 October 2009 